\title{
Research on the Cultivation and Evaluation of Students' Professional Ability in Career Technical College
}

\author{
Zhu Xiaodong \\ Information Institute \\ Ningbo City College of Vocation Technology \\ Ningbo, China \\ zxdningbo@126.com
}

\author{
Wang jing \\ Department of translation, College of foreign languages \\ Zhejiang International Studies University \\ Hangzhou, China
}

\begin{abstract}
This paper analyzes the general rules of the formation and development of professional ability. This paper discusses how to integrate the knowledge and skills in the practice of Vocational education. And make the basic professional ability and comprehensive vocational ability coordinated development. This paper puts forward a curriculum model to promote the development of vocational ability in Vocational education. The professional teachers should pay attention to the teaching strategies of the process knowledge, and the students should change their learning ideas. It is of theoretical and practical significance for vocational education to deepen and perfect the theory itself, or to establish the development path of vocational education reform and innovation.
\end{abstract}

Keywords-Career Technical College; vocational education; professional ability; professional practice; professional ability evaluation

\section{INTRODUCTION}

Vocational ability is the key content in the process of Vocational education. Strengthening the training of professional ability is very important for the graduate employment. Vocational education is the important way to develop human resources with the aim of Cultivating Vocational ability. The construction of vocational ability is not only the requirement of vocational training, but also the common requirement of all kinds of education and departments at all levels. The government should bear the general public and universal occupation ability construction, pay special attention to vulnerable groups and demobilized policy groups training opportunities. Career Technical College mainly undertakes the construction of basic and systematic vocational ability. The enterprise should be the main provider of the professional ability construction, undertake all kinds of on-thejob training related to the post skills and improve the quality of the staff. People's demands for the construction of professional ability are various, and different professional ability construction institutions should provide their own services[1].

The traditional mode of education for a long time has been focused on the quality of knowledge and neglect of moral education, pay attention to the common neglect of light personality education. This emphasis on performance and contempt for the ability of education is bound to train a group of high energy and low energy talent. This phenomenon has changed since the concept of quality education. However, quality education is not the ultimate goal of education, but to lay the foundation and conditions for capacity building. The reform of education should change from knowledge education to quality education. The core content of education is to cultivate the ability of individuals. Each person because of the occupation and the position of the different, and the demand for their professional ability is also different. In the process of the comprehensive development of the individual, the professional ability plays a leading role, and the full development of the professional ability is an important part of the all-round development of the people.

\section{VOCATIONAL EDUCATION AND VOCATIONAL ABILITY}

Vocational education is a kind of complex educational activities, and its understanding of the concept is complex and diverse. At present, the definition of "Vocational Education" is not the same. Vocational education is an important part of national education. Occupation education is mainly responsible for the training of hundreds of millions of high-quality workers and tens of millions of specialized talents with high skill tasks. Occupation education is for everyone, for the education of the whole society, economic and social ties with the most direct and most closely, and is closely related to the interests of the masses, is an important basis for economic and social development, improve people's livelihood, the relationship between social stability and building a harmonious learning and life-long learning society[2]. From the perspective of economic development, vocational education promotes economic development. Vocational education is the basic condition to realize the all-round development of human beings. The basic function of vocational education is to promote social development and human development. The definition of vocational education is the use of educational methods, so that everyone in accordance with their personality, access to the supply of life and fun.

From the occupation education practice point of view, it refers to all the knowledge and skills to enhance occupation of people, cultivate people's occupation attitude, so that people can be successfully engaged in some occupation education activities. Therefore, from the point of view of social reality, 
any special education (Professional Education) outside the general education is vocational education. It refers to the occupation education school, the students through the school a purposeful and planned and organized education activities to enable students to obtain knowledge, skills and attitudes of a certain occupation, in order to prepare for the future of students engaged in a certain occupation.

Vocational ability is one of the core concepts of vocational education, professional ability is the ability of individuals to engage in professional activities must have. It is the integration of knowledge, skills, attitudes and physical abilities necessary for professional activities, including basic professional skills and comprehensive vocational skills.

There is no generally accepted concept of professional competence. The professional ability in vocational education is defined as the ability of the individual to achieve certain professional tasks in the specific professional activities. With the rapid changes in technology, the connotation of vocational ability is also in great changes. It is necessary for us to understand the professional ability in the complicated relationship. Therefore, in the essence of the meaning, the professional ability can be understood as "connection", and the formation of professional ability is the formation of the relationship between knowledge and task[3].

Study on the occupation ability and related concepts have been starting from the initial focus on one occupation post emphasized knowledge and skills, experience and attitude to the development of the necessary and the importance of required starting from the occupation group key general ability and entrepreneurial ability. This is the rapid development of science and technology and the continuous updating of knowledge and the need for professional change. In the course of the research, the concept of "comprehensive vocational ability", "professional core competence", "professional key ability" and "professional competence" are put forward. Although some of the concepts are not very different, their respective emphasis is different. These concepts are explained from different sides. These concepts provide a useful perspective for people to understand their professional competence. It is not only of great theoretical significance, but also of practical significance to correctly understand the professional competence.

\section{Cultivation OF Professional ABILITy}

Occupation ability is a must have the occupation skills, it is necessary to integrate occupation activities of knowledge and skills, attitude and physical abilities, including basic occupation ability and comprehensive occupation ability. The cultivation of vocational skills includes the formation of knowledge, skills, attitudes and the cultivation of physical ability, and the formation and promotion of vocational ability is based on the matching mechanism of basic professional ability and comprehensive vocational ability.

The fundamental difference between vocational education and general education lies in the cultivation of Vocational skills. These two abilities constitute the main structure of the development of self. If knowledge is the power of thought, skill is the ability to act. The purpose of knowledge learning is to understand and apply. Skills are formed through a process of constant practice and gradual development. Skill learning process is generally composed of the following four stages.

The first stage is the initial stage in which people learn a certain skill. The first is to observe the case or accept the guidance, and then imitate. The whole skill is broken down into a number of units, and then one by one to imitate. During this period, the main task of students is to observe and imitate. The teacher gives each skill unit a very detailed presentation to the students, and the presentation time should be well controlled. If the teacher is too long, the students will be bored. However, if the presentation time is too short, students will not be able to master the basic skills.

The second stage is based on the decomposition of the skills on the basis of imitation, after repeated practice, students can gradually be linked to various local actions and steps, the initial completion of continuous action or thinking process[4]. The difficulty is how to stage students in linking each skill unit, so the key lies in clarifying the relationship between the teachers of each skill unit, so that students can master the skills of each unit the overall dispersion, and can digest.

The third stage is on the basis of the overall grasp, and then through continuous practice will be able to master skills. This stage is dominated by the students' practice, exercise is to enable students to achieve Practice makes perfect. When the students to the whole set of skills to operate with ease, the next action after the completion of an action naturally followed, the rules completely dominate the behavior of people, that is, procedural knowledge (skills) to achieve proficiency. The teacher's task is to guide the students to carry out systematic and purposeful exercises, on the other hand, to solve the difficult problems in the practice of the students. It should be pointed out that the special training is an important part in the development of skills, and the special training is one of the key factors in the process of skill training with its high complexity and delicacy.

The fourth stage is on the basis of the ability of the technology, according to the changes in the situation, the successful application of the relevant concepts and rules of the ability to control and regulate their behavior, flexible, rapid and accurate completion of skills. The formation of skills depends mainly on practice. The effect of practice is often determined by the way of practice. Practice has proved that in the course of the exercise will be divided into several paragraphs of the task step by step to get the best results. In the process of decomposition and imitation, the focus of the practice is the basic operation of each skill unit. In the process of mastering the whole, the continuity of the whole process is the focus of practice. And the coordination of skilled stage, the focus of practice is the skill of the operation of the skilled and skilled to be able to use.

The influence of school education on vocational ability is very important. The school education not only has the plan, the organization to teach the specialized knowledge and the ability standard to the student system, but also through the various activities to train, to train the student certain behavior custom. Teachers, teaching, activities, environment and other factors have an impact on the formation of students' professional 
ability. Teachers are always the most important objective factors that influence the formation and development of students' professional ability[5].

First of all, teachers' professional knowledge can promote students to form the basic knowledge base. Secondly, through the personal communication between teachers and students, it can have a profound impact on the formation and development of students' professional ability. The teacher's words and deeds not only provide role models for students' occupation behavior, and with the students' level of understanding, the teacher's words and deeds of the value will be more and more obvious. Many people think that the important task of vocational education is to enable students to master the basic knowledge, basic skills[6,7]. Only this is not enough, we should also train students' good professional personality as one of the important tasks. The teaching content and scope of the vocational school are wide, and the setting of the specialty has the meaning of "guidance". By teaching students the cultural and scientific knowledge of the system, the students have the basic skills and skills. Cultivate and develop students' intelligence and ability. Improve the comprehensive quality of students. At the same time, vocational education, vocational education, vocational values education is indispensable, vocational school education is different from the essence of Vocational training.

Refers to the practical curriculum is one of the leading forces in the training of students' professional ability. It plays an important role in the formation and development of students' ability. Practice is the source and motive force of the formation and development of students' professional ability. Influence of school environment for the formation and development of students' occupation ability is also a factor that can't be ignored, the organization of the school environment, including classroom atmosphere, learning atmosphere, teaching attitude, collective opinion, interpersonal relationship, campus culture, impact on students' occupation ability formation and development is irreplaceable[8].

\section{Assessment of Professional Competence}

The purpose of education is to cause the change of students' behavior, and to evaluate the learning result of education, it is necessary to test it. The general purpose of the examination system is to examine the results of the study, consolidate the results of the study, and evaluate the results of the study. The examination of vocational education is also a means to test the quality of Vocational education. However, as the occupation education learning outcomes (occupation ability), in the process of its formation and promotion can't through the examination to test, so, how to evaluate, is not only the continuation of the process of the occupation ability training, but also the outcome of the test at the same time. The content and form of evaluation should not only meet the utilitarian requirements of employment, but also achieve the goal of human nature. The evaluation of vocational ability refers to the evaluation of the professional ability and the certification of professional competence in vocational education.

With the continuous development and maturity of the mind and body measurement technology, the application of psychological measurement technology in personnel assessment is becoming more and more extensive. For all aspects of the ability to assess the tools continue to appear. Different evaluation purposes, the selection and application of competency evaluation methods should be different, how to reflect the evaluation of the ability of organic elements and elements of synergy, is an important issue in the current theory is not resolved. At present, more and more attention has been paid to the evaluation of the professional ability of the employees in our country[9]. The vocational ability of the students in vocational education is in the initial stage, and the evaluation of the current vocational ability of vocational school students is still in its infancy. Although there are a small number of students for the evaluation of the project, the evaluation methods also have the following problems.

Evaluation content is not reasonable. The existing evaluation methods are heavy knowledge, neglect ability. The evaluation of vocational education students' professional ability is only the knowledge evaluation, through the examination paper, the high score for the high quality, and low score is divided into low quality. This method lacks a clear understanding of the connotation of quality. There are evaluation of educational qualifications, that the high degree of education is identified as high quality, that low qualifications as low quality. This method is extremely unfavorable for vocational education students. In fact, ability is more important than knowledge, in the evaluation of the ability to increase the weight of the elements, in order to better predict future performance[10].

In the testing process, there is no standard for the evaluation index and weight. The evaluation index is the goal to be achieved. The evaluation index should be selected according to the object of evaluation, the purpose and requirements of the evaluation. Now the various evaluation methods in the selection of evaluation indicators are often based on the experience of arbitrary choice, there is no established scientific standards.

The current evaluation criteria are vague. This is the lack of standards, standard deviation, difficult to accurately quantify the problem. Due to the use of a lack of standards or not related to the evaluation of the professional ability of personnel, it is easy to lead to a comprehensive, objective and impartial judgment. It is difficult for the evaluation criteria to make the evaluation result convincing. The correct and effective test can be the students' understanding of the progress of their own learning and the current level of ability, and improve and enhance the effectiveness of personal learning. Help students to determine the direction of their efforts and make further career planning based on different levels of competency standards. As for the enterprise or the employing unit, it is possible to take the vocational qualification certificate as the benchmark of the post ability as the basis for assessing the staff. It is helpful for the enterprise to make judgment on the knowledge and skills acquired in the work. This can be used as the standard of professional ability. For schools or training institutions, the ability to evaluate their own training system can achieve the purpose of training to make accurate judgments. This helps determine training needs[11]. This helps improve the reputation of schools and institutions to win more students. 
The standard of professional ability is the standard of quality evaluation for students, which provides the standard of cultural knowledge, practical skills and ideological quality of the employees in different positions in the industry. The State shall issue an international qualification certificate to the qualified person, and the professional competency standards will improve the quality and consistency of current and future working hours. The content of the competency standard describes what kind of work should be done, to what extent, to what kind of quality to complete the work to be qualified and so on. Competency standards address the various positions in the field of personnel should be what work.

\section{SUMmary AND PROSPECT}

Vocational education plays an important role in improving the professional ability of human resources and promoting the construction of human resources professional ability. The key work of vocational education mainly includes three parts. The first is to train students from high degree to high ability. With the development of society, the standard of evaluating talents has changed a lot in reality. It is generally accepted that education does not represent ability. The test standard should change from "skill qualification" to "professional competence certification". Traditionally, diploma and professional qualification certificate are the main forms of professional competence certification. To carry out the certification of professional ability has a guiding role in promoting the level of human resources professional ability. School teaching should change from "knowledge + skill" to "action learning". One of the essential characteristics of vocational education is the combination of professionalism and education. The teaching reform of vocational school should be transformed from the simple combination of knowledge module and skill module to the organic combination of knowledge, skill and attitude in real professional situations. On the whole, the study of professional ability will continue to deepen, and the research methods will be more and more detailed. This research will turn from empirical and conceptual analysis to empirical and practical applications. This is the inevitable development direction of this research.

\section{REFERENCES}

[1] Duan Jinhua. Study on implementation of Vocational Teaching Reform Strategies of employment oriented research. Vocational Education Research[J]. April 2012. p51-53.

[2] Wu Jianwen, Wang Tao. Research on employment oriented practice teaching system in Higher Vocational Colleges. Vocational education [J] January 2015. p41-46.

[3] Xu Yi. Try to discuss the construction and implementation of the training mode of "micro orientation" in higher vocational education. Vocational education [J]. March 2015. p12-15.

[4] Stephen Billett(2004) . From Your Business to Our Business: Industry and VocationalEducation in Australia, Oxford Review of Education, Vol 30, No. 1, Special Issue:Business, Education and Vocationalism (Mar., 2004), pp. 13-35.

[5] A. Cortzer. Employee perceptions of their workplaces as learning environment [J]. Journal of Workplace learning,2007,16 (6).

[6] A. D, Ellinger, M. Cseh. Contextual factors influencing the facilitation of others' learning through everyday work experiences [J]. Journal of Workplace learning,2007,19 (7).

[7] A. Edwards, P. Gilroy \& D. Hartley. Rethinking Teacher Education: an Interdisciplinary Analysis [M]. London: Routledge Faimer, 2002.

[8] A. Lam. Tacit knowledge, organizational learning and societal institutions: an integratedframework[J]. Organization studies,2000,21(3).

[9] A. Styhre. Peer learning in construction work: virtuality and time in workplace learning[J]. Journal of Workplace learning,2006,18(2).

[10] A. Fox,R. Deaney,E. wilson. Examining beginning teachers' perceptions of workplace support[J]. Journal of Workplace learning, 2010,22(4).

[11] A. Hoekstra, F. Korthagen, M. Brekelmans,J. Imants. Experienced teachers' informal workplace learning and perceptions of workplace conditions [J]. Journal of Workplace learning, 2009' 21(4). 